Revue bibliographique pour le domaine irano-aryen

\title{
Richard Payne, Mehrnoush Soroush (ed.). The Archaeology of Sasanian Politics
}

\section{Rika Gyselen}

\section{(2) OpenEdition \\ 12 Journals}

\section{Édition électronique}

URL : http://journals.openedition.org/abstractairanica/42573

DOI : 10.4000/abstractairanica.42573

ISBN : 1961-960X

ISSN : 1961-960X

Éditeur :

CNRS (UMR 7528 Mondes iraniens et indiens), Éditions de l'IFRI

Référence électronique

Rika Gyselen, «Richard Payne, Mehrnoush Soroush (ed.). The Archaeology of Sasanian Politics », Abstracta Iranica [En ligne], Volume 37-38-39 | 2018, document 3, mis en ligne le 10 mars 2018, consulté le 28 septembre 2020. URL : http://journals.openedition.org/abstractairanica/42573 ; DOI : https://doi.org/10.4000/abstractairanica.42573

Ce document a été généré automatiquement le 28 septembre 2020

Tous droits réservés 


\title{
Richard Payne, Mehrnoush Soroush (ed.). The Archaeology of Sasanian Politics
}

\author{
Rika Gyselen
}

\section{RÉFÉRENCE}

Richard Payne, Mehrnoush Soroush (ed.). The Archaeology of Sasanian Politics. (Journal of Ancient History, special issue, 2.2), Berlin, De Gruyter, 2014, 136 p.

Ce volume comporte six contributions dont trois avaient été présentées à un atelier interdisciplinaire à l'Institute for the Study of the Ancient World de l'université de New York en avril 2013. L'objectif des éditeurs est de rapprocher deux disciplines: l'archéologie qui fait appel à des sources matérielles et l'histoire qui met essentiellement des données textuelles à contribution. De nombreuses autres sources ont été délibérément laissées de côté.

2 L'introduction au volume est assurée par l'un des co-éditeurs (R. Payne, "The Archaeology of Sasanian politics", p. 80-92). R.P. attribue le dynamisme que connaissent les recherches actuelles sur l'empire sassanide aux nombreux travaux archéologiques, en particulier ceux qui ont trait à ce qu'on désigne désormais comme 'landscape archaeology'. Ces nouvelles données produites par l'archéologie sont mises en rapport avec les sources littéraires qui elles sont toujours les mêmes qu'il y a un siècle.

R.P. évoque ensuite les apports des divers articles :

4 - Ses prospections dans la steppe du Mughān ont mené Karim Alizadeh à examiner la situation dans tout l'Azerbaidjan et de constater que les projets d'ériger des murs de défenses vont de pair avec ceux de développer économiquement les zones adjacentes. Il met en parallèle cette situation bien attestée dans l'Azerbaidjan avec celle, tout aussi bien connue, de l'autre côté de la mer Caspienne. 
5 - Les conclusions que tire St John Simpson des travaux dans le cadre de l'International Merv Project qui a débuté en 1992 mettent en relief le rôle de Marw qui n'est pas uniquement un lieu important d'échanges sur la route de la soie mais aussi un centre de production : textiles de coton et soie et acier au creuset.

6 - James Howard-Johnston met en rapport les données numismatiques essentiellement fournies par les trésors monétaires - et l'activité militaire. Il préconise que les futures recherches sur l'économie de l'empire sassanide s'appuient sur la coopération non seulement des archéologues et des historiens, mais aussi des numismates, ce qui semble bien être la vérité de La Palice.

7 - Les prospections dans le bassin de la rivière Kur ont permis à Tobin Hartnell de mettre en évidence que dans le Fars les projets d'irrigation et d'agriculture sont des entreprises de l'aristocratie locale contrairement à ce même type de travaux dans d'autres régions de l'empire qui émanent de la royauté.

8 - Rien d'explicite n'est formulé à propos de la contribution de Donald Whitcomb laquelle constitue en quelque sorte la conclusion au volume. L'auteur y rappelle que l'archéologie contemporaine se consacre beaucoup à la mise en évidence du développement des territoires. À l'avenir il serait bon de se concentrer plus sur la ville sassanide dont on connaît, en définitive, très peu.

9 Après bien d'autres auteurs comme R. Frye ou Ph. Gignoux qui avaient préconisé la priorité des sources primaires - en particulier les inscriptions en moyen-perse - sur la tradition historiographique, R.P. affirme que ce sont les sources archéologiques qui doivent guider l'interprétation des textes et non l'inverse.

\section{AUTEURS}

\section{RIKA GYSELEN}

CNRS, Mondes iranien et indien 